\title{
Anatomical Material and Anatomical Procurement 1954-1959
}

\author{
RUSSELL T. WOODBURNE \\ Department of Anatomy, University of Michigan Medical School, \\ Ann Arbor, Michigan
}

During the last 5 years attitudes favoring constructive alterations in statutes and procedures governing the supply of cadavers have been in evidence. A symposium conducted in 1954 at the Galveston, Texas, meeting of the American Association of Anatomists provided for an interchange of opinions and methods, and a survey presented at that symposium furnished factual information. The symposium, reported in the Proceedings of the Association (Anat. Rec., 120: 158-165), made it evident that anatomists were dealing with archaic laws in many states and were hindered in their efforts at cadaver procurement by social welfare laws and agencies, by illegitimate claimants, and by adverse popular attitudes. Favorable reports were made in the symposium, however, by those reporting frank discussions with institutional superintendents, and by those who were soliciting donations of bodies after death. It was hoped that the symposium would serve as a stimulus toward constructive efforts in the development of better anatomical laws and the use of favorable publicity.

It is gratifying that a much more favorable report can be made in 1959. In preparation for the Conference on the Legal Environment of Medical Science sponsored and organized by the National Society for Medical Research and the University of Chicago, brief replies were solicited from anatomists in the spring of 1959. Such replies gave information on changes in anatomical procurement visa-vis 1954, new or improved anatomical laws, laws providing for donation or willing of bodies, and an assessment of the "yield" from donations.

An analysis of cadaver supplies by schools was reported in the Bulletin of the National Society for Medical Research in 1955. This study showed supplies shrinking in 31 schools, fairly constant (and generally considered adequate) in 35 schools, and improved at 11 schools. Striking improvement in the situation is reflected in the replies from anatomists in 1959, where supplies were reported shrinking in only 5 states, fairly constant (and generally considered adequate) in 20 states and improved in 14 states. The reader will note that the 1955 survey was based on 77 schools and the 1959 check on 39 states. The figures are brought into approximate equivalence if those for schools are divided by 2 . The result can be expressed in the following table.

\begin{tabular}{lcc}
\hline & 1955 & $\begin{array}{c}1959 \\
\text { (States) }\end{array}$ \\
\hline Supplies shrinking & 15 & 5 \\
Supply fairly constant & & \\
$\quad$ (and generally considered & 18 & 20 \\
$\quad$ adequate) & 6 & 14 \\
\hline Supply improved & \\
\hline
\end{tabular}

It is apparent that these figures, differently gathered and differently reported, are not strictly comparable, but the trend to an improved situation nationally can hardly be denied.

It is at least defensible to consider that part of the national improvement in cadaver procurement of the past 5 years has been due to the passage of new or improved anatomical laws. Such advances have been made in 10 of the 39 states having medical schools. The states concerned are Arkansas, nlinois, Iowa, Kentucky, Louisiana, Michigan, Mississippi, Oklahoma, Texas, and West Virginia. These new or improved laws have generally made rules more specific, tightened up on claimants, and changed permissive procedures to mandatory ones. 
Another factor leading to the present improved situation in cadaver supply is the marked increase in bequest laws that have been passed in the various states. In 1954 only 10 states had statutes providing for the legal donation or willing of bodies or body parts. These are: Alabama, California, Florida, Georgia, Indiana, Iowa, Maine, Minnesota, New York, and North Carolina. In 1959 a total of 25 states have bequest laws on their statute books. The 15 states added during the 5-year interval are: Arizona, Arkansas, Kentucky, Illinois, Louisiana, Michigan, Missouri, Montana, Nebraska, Nevada, Oklahoma, Oregon, Texas, Utah and Washington. Similar laws are ready for consideration in South Dakota, Tennessee, and Virginia. Bequest laws are almost uniformly designed to legalize the donation of body parts as well as whole bodies and thus are of interest to a number of medical groups. They have proved attractive to legislators since they reflect popular desires and are relatively easy to pass. It is true that one can accept bodies by donation without a specific statute, but a proper "bequest law" assures the donor that he is acting legally and protects the donee from suit by relatives or other objectors to the action.

To those who look to donated bodies to obviate most of the difficulties associated with unclaimed ones, the growing yield from bequests is of particular interest. The medical schools of California receive "almost all" their cadavers from donations, and the popularity of the donations has become so great that some of the schools have had to refuse donations for varying periods of time. Including California, yields from donation are "large" in 6 states. The other states are Connecticut $(30-40 \%)$, District of Columbia (15$20 \%$ ), Florida (up to 25\%), Vermont $(30 \%)$, and Washington (25\%). One of the poorest areas for cadaver supply in 1954 was the District of Columbia. The encouragement of donations there has been one of the factors that has taken this region well out of its previous "depressed" status. In 9 states the yield from donations was characterized as "small but increasing." These states are Colorado, Indiana, Louisiana, Massachusetts, Michi- gan, Minnesota, Ohio, Oregon and Pennsylvania. Minor numbers of donated bodies are currently being received in 12 additional states while in another 12 the bequest program has had no effect or no information was forthcoming on this point. Donated bodies have several obvious advantages. They are much less likely to be claimed after receipt and they are frequently better bodies. While a few anatomists regard them as a source of trouble and a nuisance, most anatomical boards or committees consider the bequest source as one which will be most important for the future. In the face of greater social security and insurance coverage, it certainly has sufficient promise to warrant real consideration. It is the avenue to more bodies that can be explored to advantage when normal sources are proving inadequate to needs. This has been proved by many anatomists in many areas of the country (and recently in Canada, in relation to Queen's University).

As pointed out by the Committee on $\mathrm{Be}$ quests in its report to the National Conference on the Legal Environment of Medical Science, “a bequest program depends not so much on legislation as it does on good publicity and education." This has been especially shown in the experience of the California schools. A number of schools have produced brochures or printed explanations which point out the social value of the donation in relation to advances in the health sciences. Such brochures have usually been designed for the local situation and are in use in California, Iowa, Michigan, Minnesota, and Ontario. Other states have such brochures in use or preparation. It has been shown on numerous occasions by those who have encouraged donations that the fears of unfavorable public reaction have proved groundless; that, in fact, the public appears to be more broadminded concerning the use of the body in a constructive way after death than was thought possible.

As of 1959, however, bequest programs have not supplanted conventional reliance on "unclaimed" bodies, except perhaps in California. As a number of anatomists have pointed out again, there is nothing more productive than cultivating coopera- 
tive attitudes on the part of the hospital superintendents and other authorities who determine the destination of the unclaimed bodies which come under their jurisdiction. The maintenance of friendly relations with the morticians of the comunity also pays dividends.

The considerable improvement in the 5 years between 1954 and 1959 in the factors affecting anatomical procurement indicates that we are operating in a more favorable climate than pertained in previous years. New or improved anatomical and bequest legislation has met little opposition and public attitudes are quite encouraging. Anatomists are now more willing to urge constructive changes rather than "let sleeping dogs lie," and those who have been active in improving their situation have generally been successful.

Local situations require somewhat different laws so that "model" laws are not always applicable. During the sessions of the Conference on the Legal Environment of Medical Science, Drs. Zeit, Alexander, and Domm acted as a committee to define the basically necessary provisions of a proper Anatomical Act. They drew up the following 7 provisions:

1. Unclaimed bodies should belong to, or be under the control of medical schools and anatomical boards, demonstrators' associations, or some similar responsible organization.

2. A public official having charge of an unclaimed body must notify the medical school, board, association, or organization mentioned.

3. A public official must, of his own responsibility, use due diligence and a reasonable time be given in search for relatives of the presumed unclaimed body.
4. Such a body must be preserved and stored by the medical school or $b_{y}$ the agency which substitutes for the school.

5. A period of time should be specified for holding the body by the medical school or association, pending claim by relatives.

6. A medical school should be reimbursed for expenses incurred in connection with such a bouly before being required to release the body to claimants.

7. A provision for rejection or control of the supply ought to be provided for the school or organization.

During the same conference, Drs. Basmajian, Kirnmel, and Morgan and $\mathrm{Mr}$. F. C. Gale served as a committee on bequests. An extract from their report follows:

"Where specific laws governing bequests have not been enacted and where there is a real need either to improve the supply of cadavers or to legally provide organs or parts of cadavers (e.g., bone, arteries, etc.) one or the other of the following two legislative actions should be promoted:

a. A brief amendment to the existing Anatomy Act stating that any adult person may make provision by a written instrument for the disposition of his body or any part thereof to a medical school or hospital (or other specified agencies) in the interests of medical science; or

b. A statute specifically providing for the willing of one's body or body parts in the interests of medical science or for therapeutic purposes."

Matters pertaining to autopsies and tissue transplantation were also considered by the Conference. The Conference itself and the interest shown by those in attendance attest to the progress being made and still possible in anatomical procurement. 